\section{IPCC's climate change mindset}

SIR-A careful reading of the recent reports of the Intergovernmental Panel on Climate Change (IPCC) suggests that continuing uncertainties about climate may be less of a threat to rational forward planning than unwarranted certainties, or mindsets, of several years' standing. Moreover, the procedures being used for communicating analysis and policy proposals about climate change make it difficult to identify greenhouse mindsets among the handful of real facts on which is balanced the inverted pyramid of a huge mass of policy proposals ${ }^{2}$.

IPCC, set up by the World Meteorological Organization and the United Nations Environmental Programme, formed three international working groups (WGs) in November 1988 to make a scientific assessment of the problem (WG1), the potential impact of climate change (WG2) and to suggest strategies for response (WG3). Each group formed about half a dozen subgroups, each with 6-12 expert contributors. There were arrangements for editorial coordination; indeed, the project was a huge writing and editorial task. After many meetings and fax exchanges, group reports were completed in June this year ${ }^{3-5}$. IPCC continues.

Three indices of climate change temperature, rainfall and sea level attract most attention. WG1, on its 'business-as-usual' assumption, says that the likely increase of temperature by 2025 will be about $1{ }^{\circ} \mathrm{C}$, which is at the low end of predictions during the period 1987-88 (ref. 6). But WG1 acknowledges "low confidence" in its estimates of regional rainfall change, especially in regard to "timing, magnitude and regional patterns". Similarly, the WG1 estimates of sea-level change (increases of $20 \mathrm{~cm}$ by 2030 and $65 \mathrm{~cm}$ by 2100 ) are also much smaller than had previously been thought possible $^{6}$

While the two-year WG1 study properly reduced previous estimates of predicted climate change and prudently emphasized the uncertainties, WG2 is innocent of corresponding amendments. Indeed, WG2 says that, "in an ideal world", it would have assessed the impact of climate change after WG1 had completed its study, but that the need for the work to proceed in parallel precluded that. Instead, WG2's report is based on estimates of climate change generally current in 1988.

But it is not now possible to identify the inaccuracies in the $\mathrm{WG} 2$ report that derive from its unsustained assumptions. This is especially the case because WG2's 'Policymakers' Summary' is largely qualitative (except for numbers for sea-level rises). The lack of quantitative data is sometimes the consequence of uncertainty, as in the statement that it is unclear whether global agricultural potential will increase or decrease. But most potential impacts are presented more confidently, as BLACK or words "may" and "could". Overall, the lack of quantitative data in the WG2 report makes it impossible to make scale corrections of the impacts in the light of the new WG1 findings.

Where quantitative data do appear in the $\mathrm{WG} 2$ report - on sea level, in particular — the use made of them reveals a mindset towards outdated predictions, and especially towards a sea-level increase of $100 \mathrm{~cm}$, now forecast by WG1 for 2130 . WG2's first recommendation on coastal zones is, nevertheless, that there should be an effort to assess risks caused by a rise of 0.3 to $0.5 \mathrm{~m}$, implicitly acknowledging that this has not been done.

Although WG2 at first $^{7}$ used three scenarios - increases of $0.5 \mathrm{~m}, 1.0 \mathrm{~m}$ and $2.0 \mathrm{~m}$ - the final report ${ }^{4}$ does not distinguish between the impacts of the three alternatives although (in Chapter 6) rises of $1.0 \mathrm{~m}$ are mentioned 27 times, rises of $0.5 \mathrm{~m}$ or so only 6 times. Clearer evidence of the mindset is apparent in the solitary table (6.1), in which the costs of coastal protection for 50 countries are calculated only for a sea-level increase of $1.0 \mathrm{~m}$.

Inconsistencies of sea-level scenarios persist in the June 1990 version of the WG2 report, in phrases such as "nevertheless the impacts based on 1-2 metres ..." But the final version of the report (in section 5.1.2) states, "A rise of only $25 \mathrm{~cm}$ or more . . . could render uninhabitable nations such as the Maldives..." and, elsewhere, "the existence of entire countries such as the Maldives...[is] imperilled by a rise of only [sic] a few metres". In WG3, the Maldives are mentioned (among others) as nations within three metres of present sea level.

Perhaps the most striking illustration of the greenhouse mindset is to be found in the 'Policymakers' Summary' of WG3, where (in section 7.1) the vital discussion of coastal zone management begins with the statement that, on the assumption of continued high emissions, there will be an increase of "mean sea level [of] $65 \mathrm{~cm}$ (with an uncertainty range of 30 to $100 \mathrm{~cm}$ ) by the year 2100 ", and then continues, "if sea level rises by 1 metre, hundreds of thousands of square kilometres . . . could be inundated". The remaining discussion deals only with the consequences of rises of 1 metre even though the new findings of WG1 postpone that event well into the century after next.

Drafting difficulties are understandable in international committee deliberations, but the persisting inconsistencies are also valuable indicators of the mindset of many WHITE, but with the frequent use of the contributors. One must, of course, sympathize with those who have invested time in calculating the impact of events for which the predictions are then changed, but the conclusion must be that the findings of WG2 and WG3, as reported in June this year, are fatally flawed in three respects: (1) IPCC's methodology; (2) the credibility of the 1-m rise of sea level; and (3) the absence of numerical estimates in the potential impacts described by WG2.

Uncertainty is not the chief concern, for in principle that could be removed by further research. But the IPCC reports show that this has not yet been done. The more serious worry is the ease with which the prose text of documents such as these can be divorced from fact and real-world numbers by the ubiquitous word-processor, with the danger that particular conclusions about greenhouse impacts will retain their currency and force even when the assumptions on which they are based have been changed or rendered irrelevant.

This in turn raises the concern that the greenhouse problem is not merely an inverted pyramid of knowledge based on a handful of facts ${ }^{2}$, but that the facts may now be buried in a pyramid of muchmanipulated reports. Indeed, the documents circulated in June 1990 may represent the last identifiable connection between the supposed greenhouse impacts and the facts. It may, nevertheless, be some comfort that if the assessment of impacts and the devising of response strategies is to continue to be independent of more refined research, further research may not be necessary.

BRIAN J. O'BRIEN

12 Caithness Road,

Floreat Park, Western Australia 6014

1. Nature 347, 1 (1990).

2. White, R.M., Annual General Meeting of US Academy of Sciences, Washington DC, 24 April 1989

3. Scientific Assessment of Climatic Change, Report from WGI to IPCC, June 1990.

4. Potential Impacts of Climatic Change, Report from WGIl to IPCC, June 1990

5. Formulation of Response Strategies, Report from WGIll to IPCC, June 1990

6. The Changing Atmosphere: Implications for Global Security, Toronto, June 1988

7. Report of the Second Session of IPCC WGII. Paragraphs 4.2.1 and 4.7.2, Geneva (October 1989).

\section{Unicycling}

SIR - Thanks to John Maddox for giving an update on the kinematics of bicycling (Nature 346, 407; 1990). I believe the unicycle should be the optimum general exercise device. Not only does it require vigorous leg exercise, but it forces the user rhythmically to employ muscles of the abdomen, diaphragm, back and arms. Most importantly for those of us nearing tottering old age, the unicycle requires constant adjustment of balance. Anything new on the kinematics of unicycling?

JOHN A. JOHNSON

University of Nebraska Medical Center, Omaha, Nebraska 68134, USA 